\title{
Translation of Film Titles Based on Intercultural Communication
}

\author{
Jing Qin \\ Guangdong University of Foreign Studies. \\ Baiyun Road 2 ${ }^{\text {nd }}$, Baiyun district, Guangzhou city, \\ Guangdong province, China \\ Parisship@126.com
}

\section{ABSTRACT}

To illustrate cultural differences between China and the western world in translating film titles. Film industry plays a vital role in cultural communications, especially in the trend of globalization, which attaches a greater importance to film title translation than ever before. Some of theories concerning cultural differences will be discussed, including Hall's high-context and Low-context orientations and Hofstede's value dimensions. The study finds that with the help of these theories, certain translation methods can be utilized by translators to do a better job when translating titles of imported films.

Keywords: Cultural differences, Edward Hall, Hofstede, Film titles translation

Academic Discipline and Sub-Disciplines: Translation.

Subject Classification: Translation.

Type (Method/Approach): Empirical study.

Language: English

Date of Submission: 2018-04-09

Date of Acceptance: 2018-04-20

Date of Publication: 2018-04-30

ISSN: 2348-3024

Volume: 09 Issue: 01

Journal: Journal of Advances in Linguistics

Website: https://cirworld.com

This work is licensed under a Creative Commons Attribution 4.0 International License. 


\section{INTRODUCTION}

Culture varies tremendously from country to country, which may inevitably lead to culture shock. Cultural shock refers to the personal disorientation a person may feel when experiencing an unfamiliar way of life due to immigration or to visit a new country or a new culture. It is a move between social environments, or simply travel to another type of life. One of the most common culture shock involves individuals in a foreign environment. Cultural shock can be found wherever there is an intercultural communication because people of the two sides may not be familiar with the culture of the other (Huoyan, 2012:78). And this paper will discuss some cultural shocks in Hollywood films, especially in the movie names, that have been imported to China.

With the development of globalization, China has increasingly more connections with the western world, making cultural shock seen in many different fields (Toutanova, et. al 2003:170). For instance, China has been importing Hollywood films every year, allowing Chinese audiences to watch films from a total different culture (Tymoczko, 2016:14). However, this also brings about another problem: how to translate these films into Chinese so as to attract as many audiences as possible. Film titles translation must be completed in accordance with the preferential read habits or logical pattern of target audience (Lili, 2013: 24).

In order to minimize or eliminate such cultural unfamiliarity, we should learn about both cultures (Roger, 1991: 34). Culture shock and adaptation may be less troublesome if you become aware of the fundamental characteristic of the culture in which you are living or learning. Cultural awareness refers to understanding the culture's religious orientation, historical background, political system, key values and beliefs, verbal and nonverbal behaviors, family organization, social etiquette, and other similar aspects (Fillmore, et.al 1979: 48). In this paper, the title translation of films is involved in such understanding. Films are one of the most popular forms that can visually and vividly depict the background, custom, cultural connotation of one country or one culture, but also enhance the cultural communication between different regions and countries (Samovar, et.al 2017:15). All these make it important to translate the name of an English movie into an attractive Chinese one. Beautiful film title is just like a gateway leading audience to the cinema.

Aware of this, apart from the consciousness of intercultural communication, translators can utilize some translation theories, including transliteration, free translation and literal translation. And this paper will start with cultural value differences.

\section{CULTRAL VALUE DIFFERENCES}

Since the history, geography, custom, language and religion etc. are totally different between China and the western countries, their culture and value system vary tremendously (Sapir, 1921: 34). Firstly, in order to have a better understanding of cultural value differences, we should learn values in a comprehensive way.

Values are not only held by individuals, they are also the domain of the collective (Gile, 2009:33). Anderson and Taylor make this point clear by stating, "Values guide the behavior of people in society" and "shape the social norms in a given culture". In short, values underlie the qualities and actions that people consider necessary and vital to sustain their culture. They establish the standards for maintaining a culture (Samovar, et.al 2017:101). People and cultures are extremely complex. To help reduce this complexity, the expression cultural pattern can be used here, referring to culturally based beliefs, values, attitudes, and behaviors shared by members of a particular culture (Xuemei, et.al 2006:22-23). These patterns encompass the conditions that contribute to a social group's perception of the world and how they live in the world. Having a good notion about this cultural pattern will help to translate well.

\subsection{Hofstede's Value Dimensions}

Developed by Hofstede, the first classification identifies six value dimensions: individualism/collectivism, uncertainty avoidance, power distance, masculinity/femininity, long-term/short-term orientation, and indulgence/restraint, all of which are influenced and modified by culture. According to Hofstede's theory, we 
can easily define that China's culture is a typical culture of collectivism while America culture is of individualism. In collective cultures, relationships form a rigid social framework that distinguishes between ingroups and out-groups. People rely on their in-groups to look after them, and in exchange they believe they owe loyalty to that group. People are born into extended families, clans, or tribes that support and protect them in exchange for their allegiance. On the contrary, individualists are likely to belong to many groups but retain only weak ties, changing membership when desired. Hofstede's findings indicate that western democracies tend toward strong individualism. The two values produce variations in family structures, how classroom activities are conducted, the way organizations manage work groups, and even how the individual conducts social relations.

\subsection{Hall's High-Context and Low-Context Orientations}

Anthropologist Edward Hall categorizes cultures as high or low-context, depending on the degree to which meaning comes from the contextual environment rather than the words exchanged during communicative interaction. In high-context cultures, most of the meaning exchanged during an encounter is often not communicated through words. One reason that meanings frequently do not have to be started verbally in high-context cultures is because there is normally a strong level of similitude among the people. This leads to similar perceptions, experiences, and societal expectations, which produce well defined social protocols. In this culture, people often won't make their opinions very clear, but put their information into a certain communication circumstance, leaving it deduced by others. However, low-context cultures typically have considerable population diversity and tend to compartmentalize interpersonal contracts. In this culture, the verbal message contains most of the information and very little is embedded in the context or the participant's nonverbal activity (Venuti, 1995: 7). America is the typical of low-context culture while China represents the high-context culture, which makes it difficult to translate either the languages into the other (Xuemei, 2006:33). This also applies to title translations of films.

Generally, different cultures produce different languages. When translating, one must distinguish the discrepancies: names of Hollywood films are usually direct, informative and low-context, while in China, they'd better be indirect, simple, high-context. The following will give some examples.

\section{TRANSLATION OF FILMS' NAMES}

As discussed above, due to the cultural discrepancies between China and America, the way to name a film may be poles apart. Most names of English films are very concise. For instance, Speed, Inception, The Martian, Bird man, Boyhood, etc. Therefore, when translated into Chinese, they should be not only concise, but also full of fabulous rhythm and seem acceptable to the target audience. The following are some practical examples.

Speed was translated into 《生死时速》, Inception was translated into 《盗梦空间》， The Martian was translated into 《火星救援》, Boyhood was translated into 《少年时代》—_all of these translation versions have been delivered with some Chinese embellishment in an aim to reach a high-context effect. What worth mentioning is that, English movie names are usually translated into Chinese idioms of four characters which can illustrate the beauty and implication of Chinese culture. Here are more examples: Star Wars (《星球大战 》), A Space Odyssey (《太空漫游》) , All About Eve (《彗星美人》) , It Happened One Night (《一 夜风流》) , Midnight Cowboy（《午夜牛郎》）, The Best Years of Our Lives (《黄金时代》) , The Italian Job（《偷天换日》）, Catch Me If You Can（《猫鼠游戏》) etc.

Another type of English names of films is made up of name(s) of the character in it. That is because America highlights individualism and heroism. They believe a simple name is enough to illustrate the bravery of the hero in the movie (Vinay. et.al 1995:33). For example: Erin Brockovich, Temple Grandin, Bonne and Clyde, etc. 
Chinese films are seldom named by a single name of a role in them, instead, they often focus more on the theme of the whole story. If a film in China is named by a certain name in it, Chinese audiences will feel puzzled about the story and might think it an ordinary one in that it lacks aesthetic tonality. And one of the most possible consequences could be a tremendous loss in box office. Therefore, from the Chinese name one can usually tell what story the movie is going to tell.

Taking this into consideration, Erin Brockovich--a story of a single mother who endeavor to protect her legal right--can be translated into 《永不妥协》; Temple Grandin--a story of an extraordinary scientist who has autism since childhood--can be translated into 《自闭历程》; Bonne and Clyde--story about a couple who are hero thieves--can be translated into 《雌雄大盗》. From these examples we can find that in Chinese versions, there is not a single name, because a name in China can only transmit rather limited information.

Film titles are not made on a single basis and they are diverse (Lili, 2013: 15). In order to have a good translation of a movie name, there can be several translate ways. The following theories can also be adopted to title translations of films. All of these was done on the basis of realizing the differences between the two cultures. The following are some specialized translation methods that can be utilized when translating film titles.

\subsection{Literal Translation}

Literal translation, a simple and direct translation way, can be utilized when a Chinese name is precisely corresponded to the English name and the name reads beautiful and attractive enough to the Chinese audience (Schuttleworth, at, el. 1999: 87). That is to say, the Chinese version indicates that the film involves culture that is not that far away from the Chinese audience expectation.

Here are some examples. A Walk in the Clouds (《云中漫步》)；Rain Man (《雨人》)；Love Story（《爱情 故事》)；The Brave Heart（《勇敢的心》）；Pearl Harbor (《珍珠港》)；Schindler's List（《辛德勒名单》）； Modern Times (《摩登时代》); Beauty and the Beast (《美女与野兽》). As showed in these names, both versions are now unforgettable to the audience, implying that when English names can outline the story, literal translation can be adopted (Holmes, 1988:26). The advantage of this method is that the Chinese version can not only concisely pass on the information that the original name has, but also can generally outline the story.

\subsection{Transliteration}

Transliteration is used in accordance with the pronunciation of the English name (Zuyi, 1984: 76). This method is not taken only if the English name deals with a place, an event, a name of a hero that is well-known to the world. And there is no such cultural shock when people hear of any version of the film name, such as Titanic; Harry Potter; Hamlet; Casablanca, Romeo and Juliet, etc.

All these names are well-known to Chinese audience, and there is always a story that is so famous that when hearing of it, the audience will not feel confused. This kind of translation makes it clear what story the film is going to display, which can directly appeal to target audience and share the film market (Chen, 2002: 6).

\subsection{Free Translation}

Free translation deals with a method that the translation is done regardless of the original name of the film, because the translator believes that the translated version is more acceptable to Chinese audience (Feng, 2002: 34). In these films, as mentioned before, the English name may cause cultural confusions to Chinese audience because they may be put up with in a totally different cultural background. In this regard, free translation can help this problem out (Liu, 2009: 24). 
Here are some examples: Oliver Twist（《雾都孤儿》）；Sommersby（《似是故人来》）；Gone With the Wind (《乱世佳人》)；Charlie's Angles (《霹雾娇娃》)；Triangle (《恐怖游轮》)； Lolita (《一树梨花压海棠》 )；Top Gun (《壮志凌云》)；Coco（《寻梦环游记》）Etc.

This kind of translation is like the methodology of deverbalization in interpreting, that is, to have a fully understanding of the whole scenario in the movie instead of being stuck by the given English name. As we can see in these examples, the Chinese versions are all local idioms or imply some local culture, which can be easily remembered or noticed by Chinese audience. Apart from that, the movie plots are not unrelated with the Chinese name, which has a great impact like the proverb goes: one stone hits two birds.

\subsection{Literal Translation And Free Translation}

Literal translation combined with free translation is not uncommon in movie names translation. This method is used because neither literal translation nor free translation can fully depict the essence of the movie. For instance, Ghost, if translated into 《鬼魂》 or《魂魄》, will inevitably cause some misunderstanding that the audience would think it is just a horror movie about ghost. But as a matter of fact, it is a touching romantic love story. As a result, it was translated into 《人鬼情未了》. The Chinese name not only contains the word "ghost", but also emphasize on the "love"--a deep love that the hero and the heroine shared with each other is exactly the movie was produced to tell.

Another example is The Waterloo Bridge. If it was translated literally, Chinese audience will mistake it for another story about Napoleon. In fact, the movie has nothing to do with Napoleon in the slightest. Instead, it is a story backgrounded by the World War 2nd when the hero met the heroine on this very Waterloo Bridge and afterwards the heroine passed away on the bridge. The bridge is where the whole story starts and ends. In American culture, they believe that a single object can express what they want to tell as they live in a lowcontext culture. However, in China, there is almost pointless to translate literally, instead, 《魂断蓝桥》 is more acceptable and reveals the real content of the movie. It is undoubtedly injected into some Chinese culture elements about love, such as 魂（the souls of the hero and the heroine）.

Occasional, there are also some translations fail to have the same attractive affect as the original name and cause misunderstandings among Chinese audience ( Hunter, 2010: 47). For instance, the Revolution Road was translated into 《革命之路》. At sight of this Chinese name, audiences tend to believe that it is a movie about some revolution, or even some war. Some audience who like this kind of story will immediately go to cinema. What they will see, however, is not wars nor revolutions, but another love tragedy. Wrong title translations will bring wrong audiences but not target ones, which may cause tremendous loss in the box office.

By contrast, here are some successful translations: Stay (《生死停留》)；Interpreter (《翻译风波》)；The Terminator (《魔鬼终结者》)；Home Alone (《小鬼当家》)；All about Eve (《彗星美人》)；Swordfish ( 《剑鱼行动》）；Forrest Gump（《阿甘正传》）；Three Idiots (《三俊大闹宝莱坞》) , etc. Both versions of these films' names have turned out to be a success.

\section{CONCLUSION}

As is well acknowledged, any translation activity involves at least two different cultures, and is inevitable to encounter cultural barriers (Nida, 1991: 45). According to Samovar, there are seven problems that seem to cause great troubles in many intercultural encounters: seeking similarities, uncertainty reduction, diversity of communication purposes, stereotyping and prejudices, power, culture shock, and ethnocentrism (Samovar et.al 2017: 243-251). Therefore, it is not an easy work to complete a cross-cultural communication, let alone translation. 
The paper finds that cultural differences have a great impact on translation jobs, especially on film names translation because it may directly affect the box office. And this paper has listed four translation methods that can be utilized by translators after analyzing how English-speaking countries and China differ in ways of thinking and talking. Only starting from the audience perspective can make the translation outweight other film titles in the market. So film title translation requires the translators to be cautious about the cultural differences and avoid cultural barriers (Tymoczko, 2016: 45).

In most cases, translators have the advantage of being able to consult references if needed and not subject to the same constrains that interpreters must work under (Fawcett, 1997: 23). With the illustration of translations of movie titles, the paper suggests that in order to have a sound and positive effect on the translation, the translator should have a comprehensive understanding of both western cultures and Chinese culture and try to avoid translating into one that leads to misunderstandings ( Hunter, et. al 2010:47). The process of translation is much more complicated than merely taking a word from one language and replacing it with one from another language (Nord, 1988: 23). There are numerous cultural considerations that come into play. As mentioned above, the two cultures have many differences with each other, and intercultural communication and translation product a response. To avoid negative effects, translators should try to concentrate on both cultures and show respect to them.

\section{REFERENCES}

1. Chen Feng, A Forecasting Gross Revenues at the Movie Box Office [J]. University of Washington, Seattle, 2002. 7(2): 6

2. Fröhlich, B. and Plate, J. 2000. The cubic mouse: a new device for three-dimensional input. In Proceedings of the SIGCHI Conference on Human Factors in Computing Systems

3. Fawcett, P. Translation and Language: Linguistic Approaches Explained $[\mathrm{M}]$, Manchester: St Jerome.1997.

4. Fillmore, C. Kempler, D. \& Wang. W. Individual Differences in Language Ability and Language Behavior[M]. New York: Academic Press. 1979.

5. Gile Daniel. Basic Concepts and Models for Interpreter and Translator Training [M]. Amsterdam Philadelphia: John Benjamin's Publishing Company. 2009.

6. Holmes, James. The Name and Nature of Translation Studies. In Translated Papers on Literary Translation and Translation Studies [M]. Amsterdam: Rodopi. 1988.

7. Huoyan Wang. A study of college English teaching model based on intercultural Communication [C]. Beijing: Peking University Press. 2012: 78

8. Hunter P. G., Schellenburg E. G.\& Schimmack U. Feelings and Perceptions of happiness and sadness induced by music: Similarities, Differences, and Mixed Emotions. Psychology of Aesthetics, Creativity and the Arts[J], 2010, 4(1): 47

9. Liu, Q. S. Analysis on American Movies on Chinese College Students from Cross-cultural Communication Perspective[J]. Journal of Hebei University of Economics and Trade. 2009. 9(2): 64

10. Ma Zuyi. A Brief History of Translation in China until 1919 [M]. Beijing: China Publishing Corporation. 1984.

11. Nida, Eugene A. Language, Culture, and Translating [M]. Shanghai: Shanghai Foreign Language Education Press, 1993. 
12. Nord, C. Translating as a Purposeful Activity: Functionalist Approaches Explained [M]. Manchester: St Jerome. 1988.

13. Roger, B. Translation and Translating: Theory and Practice [M]. London: Longman. 1991.

14. Samovar, L. A., Porter, R. E. \& Roy, C. S. Cross-cultural Communication [M]. Beijing: Peking University Press. 2017.

15. Sapir, E.T. An Introduction to the Study of Speech [M]. New York: Harcourt Brace \& Company.1921.

16. Schuttleworth, M. \& Cowie, M. Dictionary of Translation Studies [M]. Manchester: St. Jerome. 1999.

17. Toutanova K., Klein D., Manning C. D. \& Singer Y. the Association for Computational Linguistics on Human Language [M]. Amsterdam: John Benjamin. 2003.

18. Tymoczko, Maria. Translation in a Postcolonial Context: Early Irish literature in English translation[M]. Routledge. 2016.

19. Vinay, J. \& Darbelnet, J. Comparative Stylistic of French and English: A Methodology of Translation[M]. Amsterdam: John Benjamin. 1995.

20. Venuti, L. The Translator's Invisibility [M] . London \& New York: Routledge. 1995.

21. Xuemei Li, Yu Zhang. Study of Chinese and Western Cultural Differences in Cross-cultural Communication [C]. Beijing: Peking University Press. 2006.

\section{Author' biography with Photo}

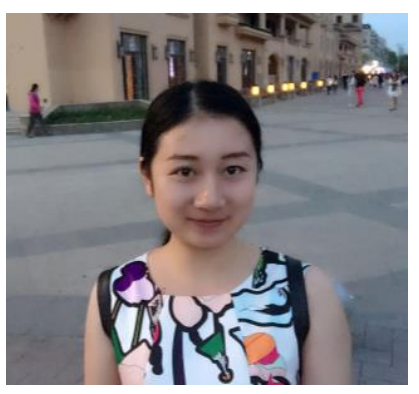

Born in the beautiful city of Guillin in 1993, the author Jing Qin is a postgraduate student of School of Interpreting And Translation Studies in Guangdong University of Foreign Studies. Supervised by professor Zhu Wenzhong, the author, majors in Interpreting, has showed a great interest in translation and interpreting studies since she was enrolled in 2017. During the winter vacation in 2017, she worked as a part-time translator in Synergy Translations, a translation company in Guangdong, China. "Translation is a significant bridge that links different cultures." said she. 